\title{
Adult T-cell leukemia/lymphoma in a Caucasian patient after sexual transmission of HTLV-1
}

\author{
David Sibon ${ }^{1,2,3^{*}}$, Olivier Cassar ${ }^{4,5}$, Isabelle Duga ${ }^{6}$, Chantal Brouzes ${ }^{7}$, David Ghez ${ }^{8}$, Christophe Pasquier ${ }^{9}$, \\ Claire Sibon $^{10}$, Alexandra Desrames ${ }^{4,5}$, Franck Mortreux ${ }^{11}$, Eric Wattel ${ }^{11}$, Ali Bazarbachi ${ }^{12}$, Antoine Gessain ${ }^{4,5}$, \\ Olivier Hermine 1,2,3 $^{2}$
}

From 17th International Conference on Human Retroviruses: HTLV and Related Viruses

Trois llets, Martinique. 18-21 June 2015

Adult T-cell leukemia/lymphoma (ATLL) is an aggressive $\mathrm{T}$-cell lymphoproliferation caused by human T-cell lymphotropic virus type-1 (HTLV-1). This oncogenic human retrovirus can be acquired by mother-to-child transmission through prolonged breast-feeding, sexual transmission, or from transfused infected blood cells or intravenous drug abuse. HTLV-1 infects approximately 5-10 million individuals worldwide and, among them, 1-5\% will develop ATLL during their lifetime. Four major geographic molecular subtypes (genotypes) have been reported including the cosmopolitan a-subtype, the Central African b-subtype, the Central African/Pygmies d-subtype and the Australo-Melanesian c-subtype. The results of several studies showed that most cases of ATLL develop in individuals who have been infected with HTLV-1 as young children via their mothers' breast milk. The very rare ATLL cases observed following transfusion or sexual transmission are still being debated. Here, we report on a Caucasian French patient, with HTLV-1-seronegative parents, who developed ATLL, characterized by a clonal T cell skin proliferation of CD4+ and CD25+ cells, 18 years after highly probable sexual transmission of HTLV-1 through repeated unprotected sexual intercourse with a Cameroonian woman. Indeed, genotyping of the patient's virus revealed infection with an HTLV-1 b-subtype strain, typically of Central African origin, especially Cameroon. This case definitively confirms the hypothesis that ATLL can develop, albeit rarely, after infection during adulthood, outside breastfeeding.

\section{Authors' details}

${ }^{1}$ Hématologie Adulte, Hôpital Universitaire Necker-Enfants Malades, Assistance Publique- Hôpitaux de Paris (APHP), Paris, France. ${ }^{2}$ INSERM U1163 and CNRS ERL 8254 Bases Cellulaires et Moléculaires des Désordres Hématologiques, France. ${ }^{3}$ Institut Imagine, Université Paris DescartesSorbonne Paris Cité, Paris, France. ${ }^{4}$ Institut Pasteur, Unité d'Epidémiologie et Physiopathologie des Virus Oncogènes, Département de Virologie, Paris, France. ${ }^{5}$ CNRS, UMR 3569, Rue du Docteur Roux, F-75015 Paris, France. ${ }^{6}$ Département de Pathologie, Hôpital Purpan, Toulouse, France. ${ }^{7}$ Laboratoire d'Hématologie, Hôpital Universitaire Necker-Enfants Malades, Assistance Publique-Hôpitaux de Paris (APHP), Paris, France. ${ }^{8}$ Hématologie, Institut Gustave-Roussy, Villejuif, France. 'Laboratoire de Virologie, Hôpital Purpan, Toulouse, France. ${ }^{10}$ Département de Dermatologie, Hôpital Ambroise-Paré, Boulogne-Billancourt, France. " 'Laboratoire d'Oncovirologie et Biothérapies, CNRS UMR 5239, Centre Hospitalier Lyon Sud, Lyon, France. ${ }^{12}$ Department of Internal Medicine, American University of Beirut, Beirut, Lebanon.

Published: 28 August 2015

doi:10.1186/1742-4690-12-S1-P76

Cite this article as: Sibon et al: Adult T-cell leukemia/lymphoma in a Caucasian patient after sexual transmission of HTLV-1. Retrovirology 2015 12(Suppl 1):P76.

Submit your next manuscript to BioMed Central and take full advantage of:

- Convenient online submission

- Thorough peer review

- No space constraints or color figure charges

- Immediate publication on acceptance

- Inclusion in PubMed, CAS, Scopus and Google Scholar

- Research which is freely available for redistribution 